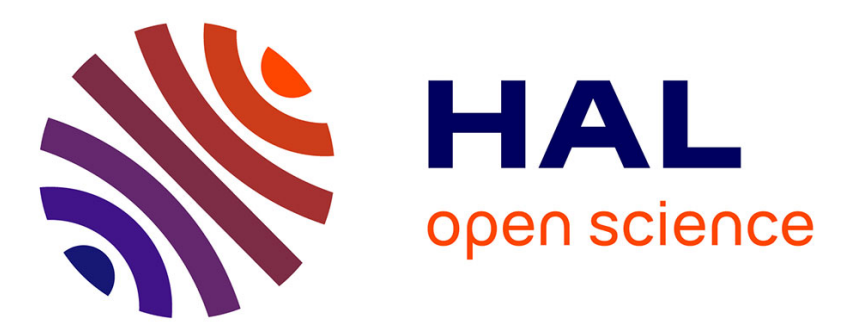

\title{
Efficient novel eutectic-mixture-mediated synthesis of benzoxazole-linked pyrrolidin-2-one heterocycles
}

Yassine Riadi, Oussama Ouerghi, Mohammed H. Geesi, Abdellah Kaiba, El Hassane Anouar, Philippe Guionneau

\section{- To cite this version:}

Yassine Riadi, Oussama Ouerghi, Mohammed H. Geesi, Abdellah Kaiba, El Hassane Anouar, et al.. Efficient novel eutectic-mixture-mediated synthesis of benzoxazole-linked pyrrolidin-2-one heterocycles. Journal of Molecular Liquids, 2021, 323, 115011 (9 p.). 10.1016/j.molliq.2020.115011 . hal-03102378

\section{HAL Id: hal-03102378 \\ https://hal.science/hal-03102378}

Submitted on 13 Jan 2021

HAL is a multi-disciplinary open access archive for the deposit and dissemination of scientific research documents, whether they are published or not. The documents may come from teaching and research institutions in France or abroad, or from public or private research centers.
L'archive ouverte pluridisciplinaire HAL, est destinée au dépôt et à la diffusion de documents scientifiques de niveau recherche, publiés ou non, émanant des établissements d'enseignement et de recherche français ou étrangers, des laboratoires publics ou privés. 
1 Efficient Novel Eutectic-Mixture-Mediated Synthesis of Benzoxazole-linked

2 Pyrrolidin-2-one Heterocycles

3 Yassine Riadi ${ }^{1 *}$, Mohammed H. Geesi ${ }^{2}$, Abdellah Kaiba ${ }^{3}$, Oussama Ouerghi ${ }^{3,4_{*}}$, El Hassane 4 Anouar $^{2}$, Philippe Guionneau ${ }^{5}$.

6 Department of Pharmaceutical Chemistry, College of Pharmacy, Prince Sattam bin Abdulaziz University, Al-Kharj 11942, Saudi Arabia

${ }^{2}$ Department of Chemistry, College of science and humanities in Al-Kharj, Prince Sattam bin Abdulaziz University, Al-Kharj 11942, Saudi Arabia

${ }^{3}$ Department of physic, College of science and humanities in Al-Kharj, Prince Sattam bin Abdulaziz University, Al-Kharj 11942, Saudi Arabia

${ }^{4}$ Université Tunis El Manar, Tunis 1068, Tunisia.

${ }^{5}$ CNRS, Univ. Bordeaux, Bordeaux INP, ICMCB, UMR 5026, 87 av. Dr A. Schweitzer, F-33600 Pessac, France.

* Corresponding author. Tel.: +966 5374931 75; e-mail: yassinriadi@yahoo.fr/oussamaouerghi@yahoo.com

\section{Abstract}

In this study, new benzoxazole-linked pyrrolidinone heterocyclic compounds were synthesized by an eco-efficient strategy using substituted benzylamines and 2-aminophenol under ultrasonic irradiation in the presence of a newly designed metal-free deep eutectic solvent (DES). This DES was prepared by using a eutectic mixture of urea and a synthesized glycine-derived ionic liquid.

22 X-ray diffraction and infrared spectroscopy were employed to investigate the structure of the 23 ionic liquid and characterize the DES, respectively.

24 This method exhibited key advantages of high productivity, a short reaction time, and simple 25 processing. Moreover, this DES was easily separated from reaction mixtures and can be recycled for multiple reactions.

Keywords: pyrrolidinone, benzoxazole moiety, ionic liquid, eutectic mixture, glycine derivative. 
31 The last two decades has witnessed a rapid increase in the applications of deep eutectic solvents 32 (DESs) as a green alternative to standard organic solvents and ionic liquids (IL). Historically, DESs are prepared by the simple mixing of hydrogen bond acceptors (HBAs); generally, a quaternary ammonium salt, e.g., choline chloride $(\mathrm{ChCl}) . \mathrm{ChCl}$ is typically used, in addition to hydrogen-bond donor (HBD) molecules such as amines, amides, alcohols, carboxylic acids, and metal salts, etc. to form a eutectic mixture linked via hydrogen-bond interactions, which is characterized by a melting point less than those of its individual precursor components [1,2]. Conceptually, the interactions between HBDs and salts disturb the electrostatic forces between anions and cations, leading to the decrease in the freezing point of the mixture [3]. DESs are typically used as an environmentally-benign reaction medium in organic chemistry as an alternative to standard organic solvents or IL. In addition, they have been utilized in a wide range of applications, including polymer synthesis, metal electrodeposition and electropolishing [4,5], as well as for the growth of nanomaterials with well-controlled shapes and dimensions. Additional applications span the solubility of biomaterials such as chitin or cellulose as well as extraction and separation, such as the separation of phenol compounds from oils [6-12]. Recently, diverse approaches based on the use of cost-effective, renewable and abundant raw precursor materials have been developed to synthesize new natural-based DESs with characteristics of biocompatibility, biodegradability and low toxicity, as well as facile preparation and purification. Among the DESs, urea-based DESs are attracting immense interest. The large-scale production of DESs was previously performed by mixing urea and $\mathrm{ChCl}$ $51 \quad[2,13,14]$.

52 Versatile 2-pyrrolidinone derivatives are found in different bioactive natural products. Owing to 53 their outstanding pharmaceutical features, they have aroused substantial importance due to their 54 wide applications in medicinal chemistry [15]. These scaffolds exhibit antibacterial [16], antimicrobial [17], anti-inflammatory [18], analgesic [19], anticancer [20] and anticonvulsant activities [21], as well as HIV-1 inhibitors [22]. Therefore, numerous synthetic protocols and

57 reactions have been reported for the preparation of pyrrolidinone derivatives [23-31].

58 Similarly, benzoxazole derivatives also have aroused immense interest in the scientific community due to their biological and pharmacological activities [32,33]. In fact, they have been 60 recognised to exhibit prominent antitumour [34], anticancer [35], antiviral [36] and antimicrobial 
61 [37,38] activities. Moreover, they have been utilized in several fields, including the plastic [39], 62 textile [40], and dye [41] industries.

63 Within the framework of our research program to access bio-active heterocyclic scaffolds $64[42,43]$, particularly by the development of new green strategies [44-47], new 2-pyrrolidinones 65 linked to the benzoxazole moiety were synthesized using a urea-based DES under ultrasonic 66 irradiation to access new derivatives in this study (Scheme 1). Despite this interest, to the best of 67 our knowledge, this synthesized DES has never been examined.

68

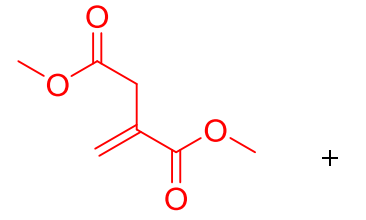

1

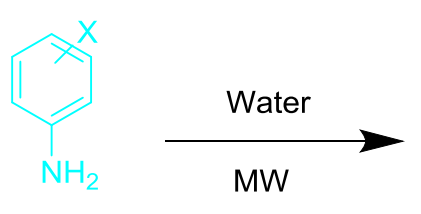

2



3

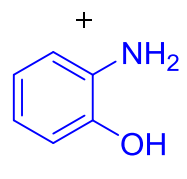

4

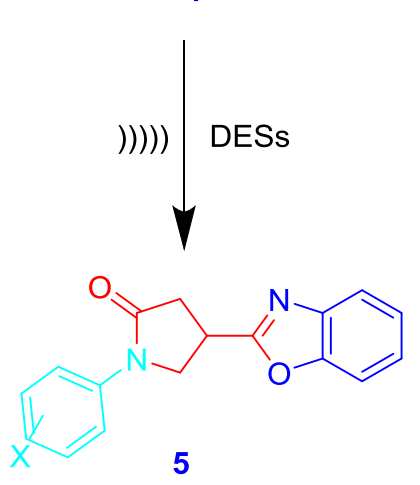

69

70

\section{2. Experimental Section}

\section{$72 \quad$ 2.1. General remarks}

73 All chemicals purchased from Sigma-Aldrich were used without any further purification.

74 Melting points of the prepared derivatives were recorded in open capillaries using a melting 
75 point apparatus (Sanyo Gallenkamp, South Borough, UK). Pre-coated silica gel TLC plates 76 (0.25-mm silica gel, 60G F254, Merck, Germany) were employed for TLC experiments. The

77 mobile-phase system used for developing TLC plates comprised a mixture of $n$-hexane:EtOAc $78(80: 20 \mathrm{v} / \mathrm{v})$. Fourier transform infrared (FTIR) spectra were recorded on a Thermo Scientific 79 Nicolet iS50 FTIR spectrometer. Viscosity was measured using an Ostwald viscometer. The total number of protons and carbons as well the environment were elucidated by recording ${ }^{1} \mathrm{H}$ NMR spectra on an NMR instrument BRUKER PLUS (400 MHz). A Biotage Initiator microwave

82 reactor and an UP200Ht ultrasonic processor with a frequency of $20 \mathrm{kHz}$ were used for the experiments.

\subsection{Synthesis of carboxymethanamonium chloride (CMAC)}

The target compound was prepared as follows: 2-Aminoacetic acid (0.0133 mol, $1 \mathrm{~g})$ was dissolved in distilled water and protonated by the dropwise addition of $1.14 \mathrm{~mL}$ of hydrochloric acid. The mixture was magnetically stirred at $80{ }^{\circ} \mathrm{C}$ for $60 \mathrm{~min}$. The resulting solution was allowed to spontaneously evaporate at room temperature. Transparent rod-like structures with suitable dimensions for crystallographic investigation were formed. The structure of the asprepared compound was theoretically solved, and its formula was estimated to be $\mathrm{C}_{2} \mathrm{NO}_{2} \mathrm{H}_{6}, \mathrm{Cl}$.

\subsection{General preparation procedure for DES}

First, a mixture of CMAC $(1 \mathrm{mmol})$ and urea $(3.5 \mathrm{mmol})$ was ground in a mortar, followed by heating at $80{ }^{\circ} \mathrm{C}$ for $15 \mathrm{~min}$. Finally, it was kept in an airtight container until further use. The mixture was visibly a fluid at room temperature.

\subsection{General synthetic procedure for derivatives 3 and 5}

\subsubsection{General methods to access derivative type 3}

First, a mixture of substituted arylamine $(15 \mathrm{mmol})$ and an equimolar amount of dimethyl itaconate $(15 \mathrm{mmol})$ was irradiated by microwaves in the presence of water as a solvent. Second, after 20 min of irradiation, ice was added to the mixture. The obtained solid was filtered and then washed with ethanol to obtain pure derivative type $\mathbf{3}$. 


\subsubsection{General synthetic procedure for derivatives type 5}

First, a mixture of methyl-1-(substituted phenyl)-5-oxopyrrolidine-3-carboxylate $(1 \mathrm{mmol})$ and 2-aminophenol (1 mmol) in DES (1 g) was irradiated for an appropriate time. Second, the reaction mixture was cooled to room temperature. Next, the mixture was poured in a beaker containing $50 \mathrm{~mL}$ of water and stirred for $10 \mathrm{~min}$, and the crude product was filtered. Finally, the compounds were further purified over a chromatography column using n-hexane:EtOAc (80:20 $\mathrm{v} / \mathrm{v})$ as the eluent

\subsection{Theoretical study}

Geometry optimization of the reactants $\mathbf{3}$ and $\mathbf{4}$ in the absence and presence of DES was performed by density functional theory (DFT) at the B3LYP/6-31++G(d,p) level of theory as implemented in the Gaussian 16 software [48]. Frequency calculations performed at the same level of theory confirmed that the optimized geometries are true minima. The effect of DES on the reactivity was investigated by determining the electronic energies and probable hydrogen bonds that may form between the reactants and DES.

\section{Results and discussion}

\subsection{X-ray diffraction analysis of CMAC}

Table 1 summarizes the collected crystal data processed at room temperature and structure refinement. Data were collected on a Nonius Kappa CCD diffractometer with a molybdenum anticathode. The $\phi$ and $\omega$ scan modes were adopted, with a crystal-detector distance of $35 \mathrm{~mm}$. The value of its mosaicity degree was $1.48^{\circ}$. The DENZO-SMN program was utilized to reduce data. The SIR 97 program permitted the structural hypothesis [48], which was refined by fullmatrix least-squares methods based on $\mathrm{F}^{2}$ with the SHELX 97 program [49]. Hydrogen atoms were located theoretically and refined isotropically. All these programs were used within the WINGX package [50]. The MERCURY [51] software was used for all graphics. Crystallographic data were deposited in the Cambridge Crystallographic Data Centre CCDC No. CCDC2012265 and can also be acquired freely at www.ccdc.cam.ac.uk/data_request/cif.

\section{Table 1}

Crystallographic data for CMAC 


\begin{tabular}{|l|l|}
\hline \hline Empirical formula & $\mathrm{C}_{2} \mathrm{H}_{6} \mathrm{Cl} \mathrm{N} \mathrm{O}_{2}$ \\
Formula weight & 111.53 \\
Temperature & $293(2) \mathrm{K}$ \\
Wavelength & $0.71069 \AA$ \\
Crystal system & Monoclinic \\
Space group & $\mathrm{P} 21 / \mathrm{c}$ \\
Unit cell dimensions & $\mathrm{a}=7.146(5) \AA$ \\
& $\mathrm{b}=5.238(5) \AA$ \\
Volume & $\mathrm{c}=13.739(5) \AA$ \\
$\mathrm{Z}$ & $510.0(6) \AA^{3}$ \\
Density (calculated) & 4 \\
Absorption coefficient & $1.452 \mathrm{Mg} / \mathrm{m}^{3}$ \\
F(000) & $0.619 \mathrm{~mm}^{-1}$ \\
Crystal size & 232 \\
Theta range for data collection & $0.12 \mathrm{x} 0.05 \mathrm{x} 0.05 \mathrm{~mm}^{3}$ \\
Index ranges & 2.990 to $26.351^{\circ}$. \\
Reflections collected & $-8<=\mathrm{h}<=8,-6<=\mathrm{k}<=6,-17<=1<=17$ \\
Independent reflections & 2626 \\
Completeness to theta $=25.240^{\circ}$ & $1021[\mathrm{R}(\mathrm{int})=0.0326]$ \\
Refinement method & $98.3 \%$ \\
Data / restraints / parameters & Full-matrix least-squares on $\mathrm{F}^{2}$ \\
Goodness-of-fit on $\mathrm{F}^{2}$ & $1021 / 0 / 55$ \\
Final R indices [I 2 sigma(I)] & 1.075 \\
R indices (all data) & $\mathrm{R} 1=0.0369, \mathrm{wR} 2=0.1049$ \\
Largest diff. peak and hole & $\mathrm{R} 1=0.0468, \mathrm{wR} 2=0.1095$ \\
\hline
\end{tabular}

\subsection{Crystal structure}

The compound crystallized in the monoclinic system with the P 21/c space group, with unit cell parameters $a=7.146(5) \AA, b=5.238(5) \AA, c=13.739(5) \AA, \beta=97.357(5)^{\circ}$, volume $510.0(6) \AA^{3}$ and $\mathrm{Z}=4$ (Table 1). The asymmetric unit included one chloride anion and one protonated cation of 2-aminoacetic acid (Fig. 1A). Cohesion was ensured by hydrogen bonds between the ${ }^{+} \mathrm{NH}_{3}$ $\mathrm{CH}_{2}-\mathrm{COOH}$ cationic group and the chloride anion $\mathrm{Cl}^{-}$via $\mathrm{N}-\mathrm{H} \cdots \mathrm{Cl}, \mathrm{OH} \cdots \mathrm{Cl}$ and $\mathrm{C}=\mathrm{O} \cdots \mathrm{H}-\mathrm{N}$ hydrogen-bond interactions. Indeed, hydrogen-bond distances were $\mathrm{d}_{\mathrm{NH} \ldots \mathrm{Cl}}=2.317 \AA$ for $\mathrm{N}$ $\mathrm{H} \cdots \mathrm{Cl}, \mathrm{d}_{\mathrm{OH} \ldots \mathrm{Cl}}=2.193 \AA$ for $\mathrm{OH} \cdots \mathrm{Cl}$ and $\mathrm{d}_{\mathrm{C}=\mathrm{O} \ldots \mathrm{HN}}=3.003 \AA$ for $\mathrm{C}=\mathrm{O} \cdots \mathrm{Cl}$. A three-dimensional framework was formed as a result of the H-bonding network. The structure also can be described as an alternation of anionic and cationic layers along the a axis (Fig. 1B). 
Fig. 1. (A) Asymmetric unit of CMAC (B) Crystal packing of the titled compound projected onto the $\mathrm{b}$ axis. Dashed lines represent $\mathrm{N}-\mathrm{H} \cdots \mathrm{Cl}, \mathrm{C}-\mathrm{OH} \cdots \mathrm{Cl}$ and $\mathrm{C}=\mathrm{O} \cdots \mathrm{H}-\mathrm{N}$ hydrogen bonds.

\section{4}

\subsection{Infrared analysis of CMAC/urea deep eutectic solvent}

Fig. 2 shows the Fourier transform infrared (FTIR) spectra of the prepared CMAC, free urea and the CMAC/urea mixture. Table 2 lists the band positions of the major characteristic vibrations as well as their assignments.

170 vibrations. The characteristic $\mathrm{C}=\mathrm{O}$ stretching peak for the carboxyl group in CMAC was 171 observed at around $1743 \mathrm{~cm}^{-1}$. Two neighbouring bands at $\sim 1589$ and $1491 \mathrm{~cm}^{-1}$ corresponded 172 to the asymmetric and symmetric $\mathrm{NH}_{3}{ }^{+}$deformation vibrations, respectively. IR bands at 1422 
173 and $1339 \mathrm{~cm}^{-1}$ corresponded to the $\mathrm{CH}_{2}$ bending and $\mathrm{CH}_{2}$ wagging vibrations, respectively. 174 Peaks at around 1220, 1123 and $1043 \mathrm{~cm}^{-1}$ corresponded to $\mathrm{CO}$ stretching, $\mathrm{NH}_{3}{ }^{+}$rocking and $\mathrm{CN}$ 175 stretching, respectively. C-C stretching vibrations were observed at 1031 and $894 \mathrm{~cm}^{-1}$ in the 176 FTIR spectrum. The sharp band at $638 \mathrm{~cm}^{-1}$ corresponded to the $\mathrm{CO}$ deformation vibration.

177 On the other hand, the FTIR spectrum relative to the CMAC/urea composite was characterized 178 by a slight shift and enlarged peaks with respect to those of pure CMAC, in addition to the 179 appearance of a new peak located at $1546 \mathrm{~cm}^{-1}$, corresponding to the amine deformation 180 vibration of urea. Considering the negligible shift of the peaks of CMAC in the CMAC/urea 181 composite, the interaction of urea with CMAC was extremely weak apparently, which was 182 ensured by the formation of a combination of hydrogen-bond interactions; this result was in 183 184 agreement with an earlier reported study suggesting that urea interacts less often with polar or 185 pure substances is explained in part by the presence of these hydrogen bonds in their structures charged molecules [52]. Generally, the depression of the melting points of DESs compared to $186[53]$.
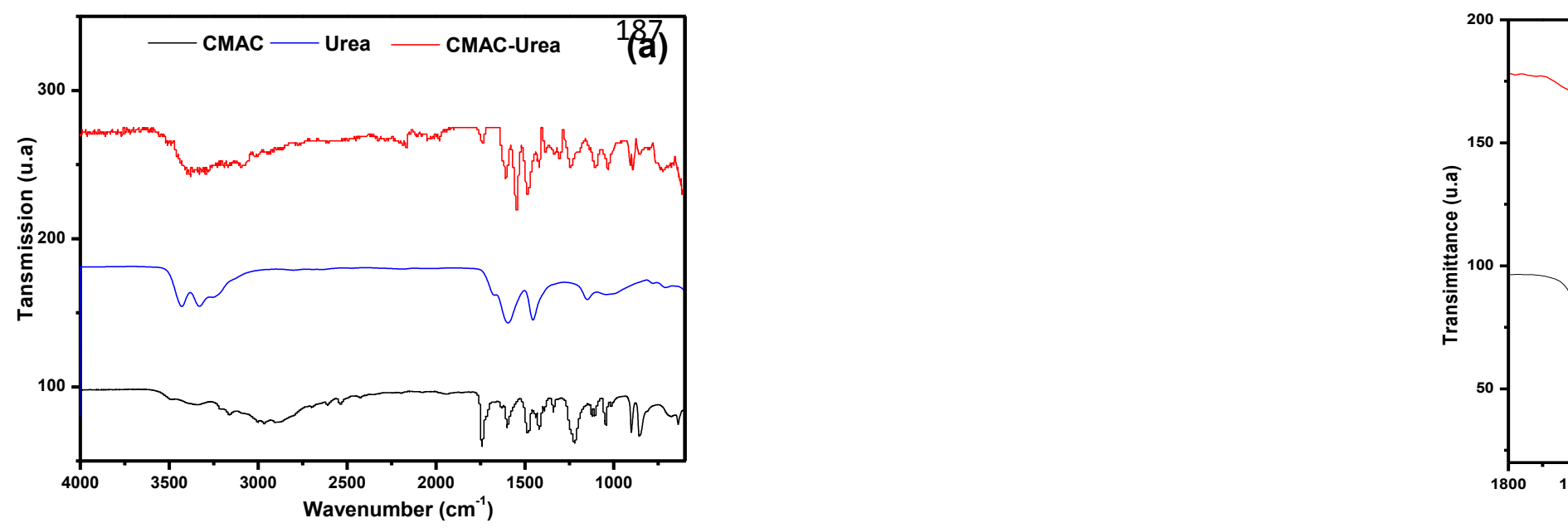

188

189 Fig. 2. Fourier transform infrared (FTIR) spectra of CMAC, free urea and CMAC/urea (a), 190 Magnified FTIR spectra showing the fingerprint regions for $\mathrm{C}=\mathrm{O}$ and $\mathrm{NH}_{2}$ stretching vibrations 191 (b).

Table 2 


\begin{tabular}{|c|c|c|c|}
\hline CMAC & & CMAC/Urea & \\
\hline Wavenumber $\left(\mathrm{cm}^{-1}\right)$ & Assignments [54] & Wavenumber $\left(\mathrm{cm}^{-1}\right)$ & Assignments \\
\hline $2300-3500$ & $\mathrm{NH}_{3}{ }^{+}$stretching and deformation & $2700-3400$ & NH stretching \\
\hline 1741 & $\mathrm{C}=\mathrm{O}$ str of $\mathrm{COOH}$ & 1739 & $\mathrm{C}=0$ \\
\hline 1599 & Assym $\mathrm{NH}_{3}{ }^{+}$def vib & 1606 & Assym $\mathrm{NH}_{3}{ }^{+}$def vib \\
\hline 1486 & Sym $\mathrm{NH}_{3}{ }^{+}$def vib & 1546 & $\mathrm{NH}_{2}$ def \\
\hline 1422 & $\mathrm{CH}_{2}$ binding vib & 1483 & $\mathrm{Sym} \mathrm{NH}_{3}{ }^{+}$def vib \\
\hline 1339 & $\mathrm{CH}_{2}$ wagging & 1419 & $\mathrm{CH}_{2}$ binding vib \\
\hline 1220 & $\mathrm{CO}$ str & 1304 & Assym N-C-N \\
\hline 1123 & $\mathrm{NH}_{3}{ }^{+}$rokking vib & 1243 & C-C binding/C-N str \\
\hline 1043 & $\mathrm{CN}$ str vib & 1104 & $\mathrm{CN}$ str vib \\
\hline 901 & C-C Str & 1032 & $\mathrm{CN}$ str vib \\
\hline 857 & C-C Str & 894 & C-C Str \\
\hline 638 & CO def vib & 725 & $\mathrm{~N}-\mathrm{H}$ binding vib \\
\hline
\end{tabular}

\subsection{Thermal analysis (DSC)}

The thermal stability of CMAC was investigated on a differential scanning calorimetry (DSC) 214 Polyma instrument. The experiment was conducted using a $31-\mathrm{mg}$ sample between $-16{ }^{\circ} \mathrm{C}$ and $75{ }^{\circ} \mathrm{C}$ at a ramp rate of $5{ }^{\circ} \mathrm{C} / \mathrm{min}$ under a static atmosphere of nitrogen. On heating, an exothermic transition was observed at approximately $-10^{\circ} \mathrm{C}$, with an enthalpy of $-2.03(\mathrm{~J} / \mathrm{g})$, corresponding to the crystallization of this compound. In the temperature range of $-5{ }^{\circ} \mathrm{C}$ to 55 ${ }^{\circ} \mathrm{C}$, this compound was stable, while at a temperature greater than $55{ }^{\circ} \mathrm{C}$, it underwent 202 degradation (Fig. 3).

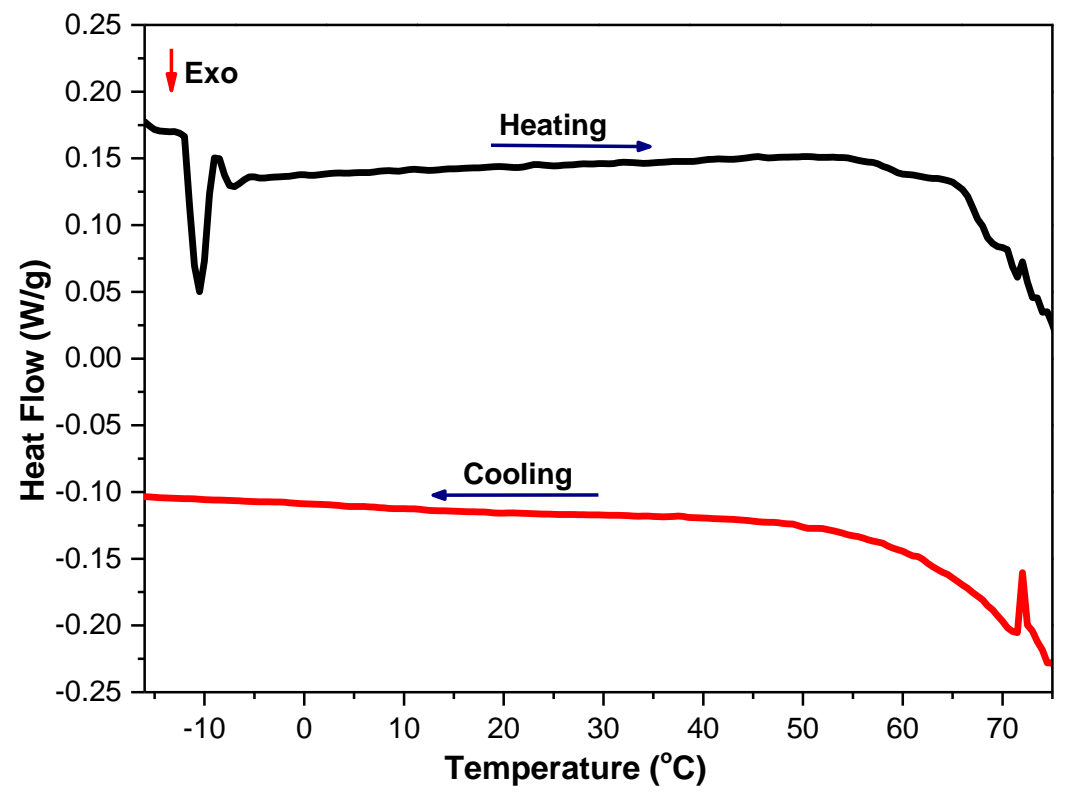




\subsection{Catalyst optimization}

216

217

218 219

220

221

222

223

224

225

226

227

228

229

230

231

232

233

234

235

236

237

To synthesize the target derivatives, intermediates methyl 5-oxo-1-arylpyrrolidine-3-carboxylate type 3 were prepared by the reaction of different arylamines with an equimolar amount of dimethyl itaconate under microwave irradiation in the presence of water as the solvent (Scheme 2).

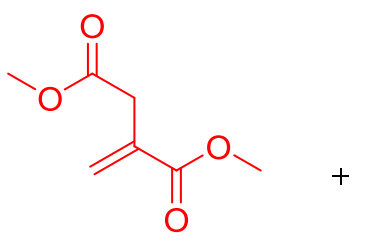

1

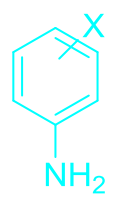

2

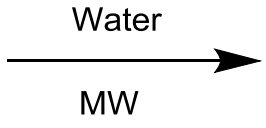

MW



3

Scheme 2. Synthetic route of 5-oxo-1-arylpyrrolidine-3-carboxylates.

\subsection{Optimization of the reaction conditions to synthesize the target derivative type 5}

Synthesis conditions were optimized by using 5-oxo-1-phenyylpyrrolidine-3-carboxylate 3a and 2-aminophenol 4 as a model reaction. Table 3 lists the effect of different DESs.

First, by using benzalkonium chloride or $\mathrm{ChCl}$ with glycerol or ethylene glycerol as the mixture, the product was obtained in low yields (Table 3, entries 1, 2, 6, and 7). On the other hand, by using a mixture of benzalkonium chloride/urea, derivative 5a was obtained in 58\% yield (Table 3, entry 3). By using a mixture of $\mathrm{ChCl} /$ urea, 5a was obtained in 55\% yield (Table 3, entry 5). Moreover, by using a mixture oxalic acid and benzalkonium chloride or $\mathrm{ChCl}$, the product was obtained in a better yield (Table 3, entries 4 and 8). The use of CMAC alone afforded a moderate product yield of $41 \%$ (Table 3, entry 9). Remarkably, by using a mixture of CMAC/urea, the product was obtained in an excellent yield in an extremely short time (Table 3, entry 10). This increased yield implied that the developed DES serves not only as a solvent but also as a catalyst for the reaction. Such dual solvent/catalyst characteristics of DESs have been reported previously by several authors [55-57]. By heating the reaction at $50^{\circ} \mathrm{C}$ or subjecting the reaction to microwave irradiation, the product was successively isolated in $22 \%$ or $83 \%$ yield, respectively. The use of urea alone afforded a trace amount of the product (Table 3, entry 13). In the presence 
238 of water or in the absence of any additive, no compound was generated (Table 3, entry 14 and 23915 , respectively).

240 Table 3

241 Optimization of the heterocycle construction.

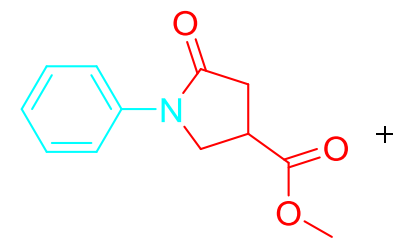

3<smiles>Nc1ccccc1O</smiles>

4


$5 a$

\begin{tabular}{|c|c|c|c|c|}
\hline Entry & Mixture of deep eutectic solvent & Condtions & Time (min) & Yield $(\%)^{\mathbf{a}}$ \\
\hline 1 & Benzalkonium chloride/glycerol & )))) & 20 & 36 \\
\hline 2 & Benzalkonium chloride/ethylene glycol & )$)))$ & 20 & 42 \\
\hline 3 & Benzalkonium chloride/urea & )$))))$ & 20 & 58 \\
\hline 4 & Benzalkonium chloride/oxalic acid & )$)))$ & 20 & 79 \\
\hline 5 & Choline chloride/urea & )$)))$ & 20 & 55 \\
\hline 6 & Choline chloride /glycerol & )$)))$ ( & 20 & 48 \\
\hline 7 & Choline chloride /ethylene glycol & )$)))$ & 20 & 51 \\
\hline 8 & Choline chloride / oxalic acid & )$))))$ & 20 & 71 \\
\hline 9 & CMAC & )))) & 30 & 41 \\
\hline 10 & CMAC/urea & )$)))$ & 20 & 88 \\
\hline 11 & CMAC/urea & $50{ }^{\circ} \mathrm{C}$ & 20 & 22 \\
\hline 12 & CMAC/urea & MW & 20 & 83 \\
\hline 13 & Urea & & 20 & Traces \\
\hline 14 & Water & & 20 & - \\
\hline 15 & - & & 20 & - \\
\hline
\end{tabular}




\subsection{Extension of the methodology}

245 First, a mixture of methyl-1-(substituted phenyl)-5-oxopyrrolidine-3-carboxylate 3 (1 mmol) and 246 2-aminophenol 4 (1 mmol) in DES (1 g) (3.5:1 molar ratio) was subjected to microwave 247 irradiation for an appropriate time. Second, the reaction mixture was irradiated till the starting 248 materials were completely converted (monitored by TLC using 80:20 v/v of hexane:AcOEt) 249 (Scheme 3). Third, the reaction mixture was cooled to room temperature. Next, the mixture was 250 poured into a beaker containing $50 \mathrm{~mL}$ of water and stirred for $10 \mathrm{~min}$, followed by the filtration 251 of the crude product. The compounds were further purified by column chromatography using n252 hexane:AcOEt $(80: 20 \mathrm{v} / \mathrm{v})$ as the eluent.

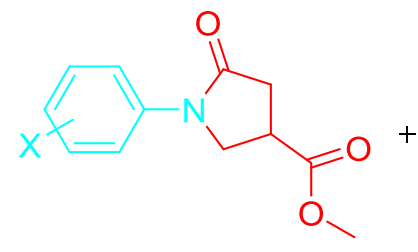

3<smiles>Nc1ccccc1O</smiles>

4

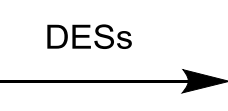

()$)))$

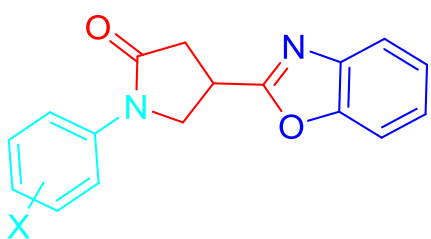

5

254 Scheme 3. Investigation of synthesis of benzoxazole-linked pyrrolidinone type $\mathbf{5}$.

255 Pyrrolidinone derivatives 5a-i were obtained in $10 \mathrm{~min}$ in excellent yields. All reactions were 256 performed using reactant type $\mathbf{3}$ and $\mathbf{4}$. The substituents linked to derivative $\mathbf{3}$ did not affect the 257 reaction, and the corresponding products were obtained in an extremely short time (10 min) in 258 high yields (Table 4). Derivatives structures of $\mathbf{5 a}-\mathbf{i}$ were confirmed by spectral characterization 259 (m.p., ${ }^{1} \mathrm{H}$ NMR and IR).

\section{Table 4}

261 Synthesis of derivatives 5a-i.

\section{Entry $\operatorname{ArNH}_{2} \quad$ Compound Yield (\%)}

1


2<smiles>Cc1ccc(Cl)cc1</smiles>

3<smiles>Cc1ccc(C)cc1</smiles>

4<smiles>COc1ccc(C)cc1</smiles>

5<smiles>Cc1ccc(O)cc1</smiles>

6<smiles>Cc1ccc([N+](=O)[O-])cc1</smiles>

7<smiles>Cc1ccc(F)c(Cl)c1</smiles>

8<smiles>Cc1ccccc1C</smiles>

$5 h$

$5 \mathbf{i}$
91

82

84

81

79

80

85

89

$262{ }^{a}$ Yield of pure isolated products. Reaction conditions: $o$-aminophenol (1 mmol), intermediate $\mathbf{3}$ (1 mmol), $2631 \mathrm{~g}$ of DES, 20 min. ${ }^{\mathrm{b}}$ Isolated yield.

264 Reusability of DESs is one of its performance criteria. Therefore, to evaluate the recycling ability 265 of the synthesized DES, the reaction is performed for four consecutive cycles. Notably, the 
266 product was obtained in excellent yield after each cycle, indicative of its possible recovery till 267 the fourth cycle.

\section{3.8. Plausible Mechanism Involved in the Formation of Product 5}

269 The reactivity of reactants might be improved by the presence of catalysts or a specific type of 270 solvent. Herein, the effect of DES on the stability of reactants 3 and $\mathbf{4}$ was determined by the 271 calculation of electronic energies in the absence and presence of DES (Fig. 4). Indeed, the DES 272 stabilized 3 and 4 by 225 Hartree. The stability of the starting material in the presence of DES 273 was mainly related to the formation of strong intermolecular hydrogen bonds between DES and 274 the starting reagents (Fig.4). Indeed, the amine group of urea (DES part) formed (i) two 275 hydrogen bonds with keto and methoxyl groups of $\mathbf{3}$, with distances $2.12 \AA$ and $2.30 \AA$, 276 respectively, and (ii) two hydrogen bonds with amine and hydroxyl groups of 4, with distances $277 \quad 2.25 \AA$ and $2.17 \AA$, respectively.
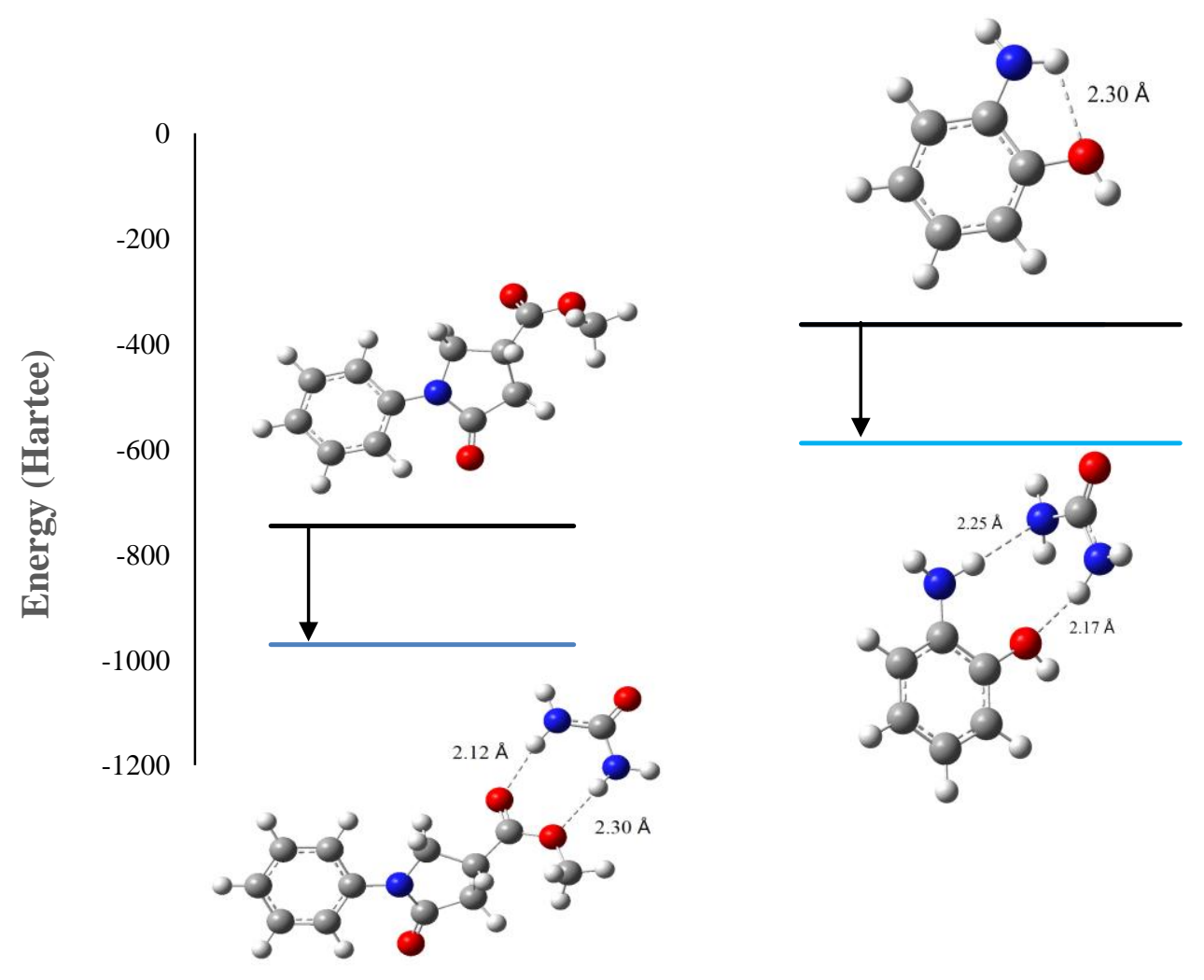

279 Fig. 4. Energetic diagram of reactants in the presence and absence of the deep eutectic solvent.

\section{Conclusion}


In summary, a green strategy for the preparation of new benzoxazole-linked pyrrolidinone heterocycles was developed by using arylamines and 2-aminophenol under ultrasonic irradiation in the presence of a newly prepared deep eutectic solvent (DES). X-ray diffraction and infrared spectroscopy were employed to investigate the structure of the ionic liquid and characterize the DES, respectively. This strategy exhibited main advantages of a short reaction time and high productivity, in addition to the simple separation of DES from reaction mixtures.

\section{References}

288

[1] D.J. Ramón, G. Guillena, Deep Eutectic Solvents: Synthesis, Properties, and Applications, John Wiley \& Sons, 2020.

[2] Q. Zhang, K.D.O. Vigier, S. Royer, F. Jerome, Deep eutectic solvents: syntheses, properties and applications, Chemical Society Reviews. 41 (2012) 7108-7146.

[3] A.P. Abbott, D. Boothby, G. Capper, D.L. Davies, R.K. Rasheed, Deep eutectic solvents formed between choline chloride and carboxylic acids: versatile alternatives to ionic liquids, Journal of the American Chemical Society. 126 (2004) 9142-9147.

[4] A.P. Abbott, K. El Ttaib, K.S. Ryder, E.L. Smith, Electrodeposition of nickel using eutectic based ionic liquids, Transactions of the IMF. 86 (2008) 234-240.

[5] A.P. Abbott, G. Capper, K.J. McKenzie, A. Glidle, K.S. Ryder, Electropolishing of stainless steels in a choline chloride based ionic liquid: an electrochemical study with surface characterisation using SEM and atomic force microscopy, Physical Chemistry Chemical Physics. 8 (2006) 4214-4221.

[6] M. Sharma, C. Mukesh, D. Mondal, K. Prasad, Dissolution of $\alpha$-chitin in deep eutectic solvents, Rsc Advances. 3 (2013) 18149-18155.

[7] J. Kadokawa, S. Idenoue, K. Yamamoto, Fabricating Chitin Paper from Self-Assembled Nanochitins, ACS Sustainable Chemistry \& Engineering. (2020).

[8] Y.-L. Chen, X. Zhang, T.-T. You, F. Xu, Deep eutectic solvents (DESs) for cellulose dissolution: A minireview, Cellulose. 26 (2019) 205-213.

[9] K. Pang, Y. Hou, W. Wu, W. Guo, W. Peng, K.N. Marsh, Efficient separation of phenols from oils via forming deep eutectic solvents, Green Chemistry. 14 (2012) 2398-2401.

[10] A.P. Abbott, P.M. Cullis, M.J. Gibson, R.C. Harris, E. Raven, Extraction of glycerol from biodiesel into a eutectic based ionic liquid, Green Chemistry. 9 (2007) 868-872.

[11] Y. Dai, J. Van Spronsen, G.-J. Witkamp, R. Verpoorte, Y.H. Choi, lonic liquids and deep eutectic solvents in natural products research: mixtures of solids as extraction solvents, Journal of Natural Products. 76 (2013) 2162-2173.

[12] F.S. Oliveira, A.B. Pereiro, L.P. Rebelo, I.M. Marrucho, Deep eutectic solvents as extraction media for azeotropic mixtures, Green Chemistry. 15 (2013) 1326-1330.

[13] X. Meng, K. Ballerat-Busserolles, P. Husson, J.-M. Andanson, Impact of water on the melting temperature of urea+ choline chloride deep eutectic solvent, New Journal of Chemistry. 40 (2016) 4492-4499.

[14] F. Chen, S. Xie, J. Zhang, R. Liu, Synthesis of spherical Fe304 magnetic nanoparticles by coprecipitation in choline chloride/urea deep eutectic solvent, Materials Letters. 112 (2013) 177-179.

[15]Z. Hosseinzadeh, A. Ramazani, K. Hosseinzadeh, N. Razzaghi-Asl, F. Gouranlou, An overview on chemistry and biological importance of pyrrolidinone, Curr Org Synth. 14 (2017) 1-13. 
[16] V.L. Gein, V.A. Mihalev, N.N. Kasimova, E.V. Voronina, M.I. Vakhrin, E.B. Babushkina, Synthesis and antibacterial activity of 1-alkoxyalkyl-5-aryl-4-acyl-3-hydroxy-3-pyrrolin-2-ones, Pharmaceutical Chemistry Journal. 41 (2007) 208-210.

[17] V.L. Gein, M.N. Armisheva, N.A. Rassudikhina, M.I. Vakhrin, E.V. Voronina, Synthesis and antimicrobial activity of 1-(4-hydroxyphenyl)-4-acyl-5-aryl-3-hydroxy-3-pyrrolin-2-ones, Pharmaceutical Chemistry Journal. 45 (2011) 162.

[18] K. Okumura, I. Inoue, M. Ikezaki, G. Hayashi, S. Nurimoto, K. Shintomi, Synthesis and antiinflammatory Activity of a series 1-Aryl-2-pyrrolidinone derivatives, Journal of Medicinal Chemistry. 9 (1966) 315-319.

[19] V.L. Gein, V.V. Yushkov, N.N. Kasimova, N.S. Shuklina, M.Y. Vasil'eva, M.V. Gubanova, Synthesis and Antiinflammatory and Analgesic Activity of 1-(2-aminoethyl)-5-aryl-4-acyl-3-hydroxy-3-pyrrolin-2ones, Pharmaceutical Chemistry Journal. 39 (2005) 484-487.

[20] Y. Geng, X. Wang, L. Yang, H. Sun, Y. Wang, Y. Zhao, R. She, M.-X. Wang, D.-X. Wang, J. Tang, Antitumor Activity of a 5-Hydroxy-1 H-Pyrrol-2-(5 H)-One-Based Synthetic Small Molecule In Vitro and In Vivo, PloS One. 10 (2015) e0128928.

[21] H. Sasaki, Y. Mori, J. Nakamura, J. Shibasaki, Synthesis and anticonvulsant activity of 1-acyl-2pyrrolidinone derivatives, Journal of Medicinal Chemistry. 34 (1991) 628-633.

[22] K. Ma, P. Wang, W. Fu, X. Wan, L. Zhou, Y. Chu, D. Ye, Rational design of 2-pyrrolinones as inhibitors of HIV-1 integrase, Bioorganic \& Medicinal Chemistry Letters. 21 (2011) 6724-6727.

[23] M.S. Franco, G.A. Casagrande, C. Raminelli, S. Moura, M. Rossatto, F.H. Quina, C.M. Pereira, A.F. Flores, L. Pizzuti, Ultrasound-promoted environmentally friendly synthesis of 5-(3, 3, 3-trifluoro-2oxopropylidene) pyrrolidin-2-ones, Synthetic Communications. 45 (2015) 692-701.

[24] M. Anada, S. Hashimoto, Enantioselective Synthesis of 4-Substituted 2-Pyrrolidinones by Siteselective $\mathrm{CH}$ Insertion of $\alpha$-Methoxycarbonyl- $\alpha$-diazoacetanilides Catalyzed by Dirhodium (II) Tetrakis [N-phthaloyl-(S)-tert-leucinate], Tetrahedron Letters. 39 (1998) 79-82.

[25] D.-R. Choi, K.-Y. Lee, Y.-S. Chung, J.-E. Joo, Y.-H. Kim, C.-Y. Oh, Y.-S. Lee, W.-H. Ham, Diastereoselective synthesis of polysubstituted pyrrolidinone as a key intermediate for the anticancer agents by palladium (II)-catalyzed carboxylation, Archives of Pharmacal Research. 28 (2005) 151-158.

[26] L.E. Burgess, A.I. Meyers, A simple asymmetric synthesis of 2-substituted pyrrolidines and 5substituted pyrrolidinones, The Journal of Organic Chemistry. 57 (1992) 1656-1662.

[27] L.E. Overman, T.P. Remarchuk, Catalytic asymmetric intramolecular aminopalladation: Enantioselective synthesis of vinyl-substituted 2-oxazolidinones, 2-imidazolidinones, and 2pyrrolidinones, Journal of the American Chemical Society. 124 (2002) 12-13.

[28] V. Singh, R. Saxena, S. Batra, Simple and efficient synthesis of substituted 2-pyrrolidinones, 2pyrrolones, and pyrrolidines from enaminones of Baylis- Hillman derivatives of 3isoxazolecarbaldehydes, The Journal of Organic Chemistry. 70 (2005) 353-356.

[29] R. Sarkar, C. Mukhopadhyay, Admicellar catalysis in multicomponent synthesis of polysubstituted pyrrolidinones, Tetrahedron Letters. 54 (2013) 3706-3711.

[30] J. Sun, Q. Wu, E.-Y. Xia, C.-G. Yan, Molecular diversity of three-component reactions of aromatic aldehydes, arylamines, and acetylenedicarboxylates, European Journal of Organic Chemistry. 2011 (2011) 2981-2986.

[31] Q. Zhu, H. Jiang, J. Li, S. Liu, C. Xia, M. Zhang, Concise and versatile multicomponent synthesis of multisubstituted polyfunctional dihydropyrroles, Journal of Combinatorial Chemistry. 11 (2009) 685-696.

[32] Y. ISOMURA, N. ITO, S. SAKAMOTO, H. HOMMA, T. ABE, K. KUBO, Studies on the synthesis and antiinflammatory activity of 2, 6-di-tert-butylphenols with a heterocyclic group at the 4-position. II, Chemical and Pharmaceutical Bulletin. 31 (1983) 3179-3185. 
[33] Y. ISOMURA, S. SAKAMOTO, N. ITO, H. HOMMA, T. ABE, K. KUBO, Synthesis and anti-inflammatory activity of 2, 6-di-tert-butylphenols with a heterocyclic group at the 4-position. III., Chemical and Pharmaceutical Bulletin. 32 (1984) 152-165.

[34] C.-C. CHENG, D.-F. LIU, T.-C. CHOU, Design of antineoplastic agents on the basis of the 2phenylnaphthalene-type'structural pattern. I: Synthesis of substituted 3-phenylquinazolones, benzoxazolo [2, 3-b] quinazolones and benzothiazolo [2, 3-b] quinazolones, Heterocycles (Sendai). 35 (1993) 775-789.

[35] J. Kočí, V. Klimešová, K. Waisser, J. Kaustová, H.-M. Dahse, U. Möllmann, Heterocyclic benzazole derivatives with antimycobacterial in vitro activity, Bioorganic \& Medicinal Chemistry Letters. 12 (2002) 3275-3278.

[36] J.M. Hoffman, A.M. Smith, C.S. Rooney, T.E. Fisher, J.S. Wai, C.M. Thomas, D.L. Bamberger, J.L. Barnes, T.M. Williams, Synthesis and evaluation of 2-pyridinone derivatives as HIV-1-specific reverse transcriptase inhibitors. 4. 3-[2-(Benzoxazol-2-yl) ethyl]-5-ethyl-6-methylpyridin-2 (1H)-one and analogs, Journal of Medicinal Chemistry. 36 (1993) 953-966.

[37] Ö.T. Arpaci, i. Ören, N. Altanlar, Synthesis and antimicrobial activity of some novel 2-(p-substitutedphenyl)-5-substituted-carbonylaminobenzoxazoles, II Farmaco. 57 (2002) 175-181.

[38] Ö. Temiz-Arpaci, E. Aki-Şener, I. Yalcin, N. Altanlar, Synthesis and Antimicrobial Activity of Some 2[p-Substituted-phenyl] benzoxazol-5-yl-arylcarboxyamides, Archiv Der Pharmazie: An International Journal Pharmaceutical and Medicinal Chemistry. 335 (2002) 283-288.

[39] K.H. Park, J.T. Lim, S. Song, M.G. Kwak, C.J. Lee, N. Kim, Nonlinear optical polymers with novel benzoxazole chromophores: IV. Synthesis of maleimide-styrene and maleimide-methacrylate copolymers, Reactive and Functional Polymers. 40 (1999) 169-175.

[40] E. Koyama, G. Yang, K. Hiratani, A novel synthesis of bis (benzoxazole) derivatives via tandem Claisen rearrangement, Tetrahedron Letters. 41 (2000) 8111-8116.

[41] S.-I. Um, The synthesis and properties of benzoxazole fluorescent brighteners for application to polyester fibers, Dyes and Pigments. 75 (2007) 185-188.

[42] Y. Riadi, M. Geesi, Photochemical route for the synthesis of novel 2-monosubstituted pyrido [2, 3-d] pyrimidines by palladium-catalyzed cross-coupling reactions, Chemical Papers. 72 (2018) 697-701.

[43] Y. Riadi, S. Massip, J.-M. Leger, C. Jarry, S. Lazar, G. Guillaumet, Convenient synthesis of 2, 4disubstituted pyrido [2, 3-d] pyrimidines via regioselective palladium-catalyzed reactions, Tetrahedron. 68 (2012) 5018-5024.

[44]Y. Riadi, R. Mamouni, R. Azzalou, M. El Haddad, S. Routier, G. Guillaumet, S. Lazar, An efficient and reusable heterogeneous catalyst animal bone meal for facile synthesis of benzimidazoles, benzoxazoles, and benzothiazoles, Tetrahedron Letters. 52 (2011) 3492-3495.

[45] Y. Riadi, R. Mamouni, S. Routier, G. Guillaumet, S. Lazar, Ecofriendly synthesis of 3-cyanopyridine derivatives by multi-component reaction catalyzed by animal bone meal, Environmental Chemistry Letters. 12 (2014) 523-527.

[46] Y. Riadi, M. Geesi, O. Dehbi, M.A. Bakht, M. Alshammari, M.-C. Viaud-Massuarde, Novel animalbone-meal-supported palladium as a green and efficient catalyst for Suzuki coupling reaction in water, under sunlight, Green Chemistry Letters and Reviews. 10 (2017) 101-106.

[47] O. Dehbi, E.A. Ishak, M.A. Bakht, M.H. Geesi, M.B. Alshammari, V. Chagnault, A. Kaiba, S. Lazar, Y. Riadi, Water-mediated synthesis of disubstituted 5-aminopyrimidines from vinyl azides under microwave irradiation, Green Chemistry Letters and Reviews. 11 (2018) 62-66.

[48] M. Frisch, G.W. Trucks, H.B. Schlegel, G.E. Scuseria, M.A. Robb, J.R. Cheeseman, G. Scalmani, V. Barone, B. Mennucci, Ga. Petersson, gaussian 09, Revision d. 01, Gaussian, Inc., Wallingford CT. 201 (2009).

[49] S. GM, SHELX-97, release 97-2, University of Göttingen, Germany. (1998). 
[50] L.J. Farrugia, WinGX suite for small-molecule single-crystal crystallography, Journal of Applied Crystallography. 32 (1999) 837-838.

[51] C.F. Macrae, I.J. Bruno, J.A. Chisholm, P.R. Edgington, P. McCabe, E. Pidcock, L. Rodriguez-Monge, R. Taylor, J.V.D. Streek, P.A. Wood, Mercury CSD 2.0-new features for the visualization and investigation of crystal structures, Journal of Applied Crystallography. 41 (2008) 466-470.

[52] M.C. Stumpe, H. Grubmüller, Interaction of urea with amino acids: implications for urea-induced protein denaturation, Journal of the American Chemical Society. 129 (2007) 16126-16131.

[53] A.P. Abbott, D. Boothby, G. Capper, D.L. Davies, R.K. Rasheed, Deep eutectic solvents formed between choline chloride and carboxylic acids: versatile alternatives to ionic liquids, Journal of the American Chemical Society. 126 (2004) 9142-9147.

[54] G. Socrates, Infrared and Raman characteristic group frequencies: tables and charts, John Wiley \& Sons, 2004.

[55] P.H. Tran, A.-H.T. Hang, Deep eutectic solvent-catalyzed arylation of benzoxazoles with aromatic aldehydes, RSC Advances. 8 (2018) 11127-11133.

[56] T.T. Nguyen, C.T. Nguyen, P.H. Tran, Synthesis of a new series of 2-hydroxy-5-iodo-N'-(1arylethylidene) benzohydrazides using a deep eutectic solvent as solvent/catalyst under sonication, Heliyon. 5 (2019) e02353.

[57] I. Dindarloo Inaloo, S. Majnooni, Deep Eutectic Solvents (DES) as Green and Efficient Solvent/Catalyst Systems for the Synthesis of Carbamates and Ureas from Carbonates, ChemistrySelect. 4 (2019) 7811-7817. 